\title{
Association Between Medicaid Expansion Under the Affordable Care Act and Medicaid-Covered Pre-emptive Kidney Transplantation
}

\author{
Meera N. Harhay, MD, MSCE ${ }^{1,2}$, Ryan M. McKenna, PhD ${ }^{3}$, and Michael O. Harhay, \\ $P h D^{4,5,6}$
}

\begin{abstract}
'Department of Medicine, Division of Nephrology and Hypertension, Drexel University College of Medicine, Philadelphia, PA, USA; ${ }^{2}$ Department of Epidemiology and Biostatistics, Drexel University Dornsife School of Public Health, Philadelphia, PA, USA; ${ }^{3}$ Department of Health Policy and Management, Drexel University Dornsife School of Public Health, Philadelphia, USA; ${ }^{4}$ Department of Biostatistics, Epidemiology and Informatics, Perelman School of Medicine, University of Pennsylvania, Philadelphia, PA, USA; ${ }^{5}$ Palliative and Advanced lliness Research (PAIR) Center, Perelman School of Medicine, University of Pennsylvania, Philadelphia, USA; 'Leonard Davis Institute of Health Economics, University of Pennsylvania,

Philadelphia, PA, USA.
\end{abstract}

$\begin{array}{ll}\text { Abbreviations } & \\ \text { ACA } & \text { Affordable Care Act } \\ \text { BMI } & \text { Body Mass Index } \\ \text { DDKT } & \text { Deceased Donor KT } \\ \text { ESKD } & \text { End-stage Kidney Disease } \\ \text { HS } & \text { High School } \\ \text { IQR } & \text { Interquartile Range } \\ \text { KT } & \text { Kidney Transplantation } \\ \text { LDKT } & \text { Living-donor KT } \\ \text { US } & \text { United States }\end{array}$

J Gen Intern Med 34(11):2322-5

DOI: $10.1007 / \mathrm{s} 11606-019-05279-\mathrm{x}$

(c) Society of General Internal Medicine 2019

\author{
Affordable Care Act \\ Deceased Donor KT \\ End-stage Kidney Disease \\ High Schoo \\ Kidney Transplantation \\ United States
}

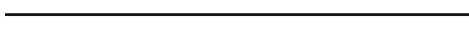

INTRODUCTION

Pre-emptive kidney transplantation (KT), or KT before the need for dialysis, is the preferred treatment for end-stage kidney disease (ESKD). ${ }^{1}$ However, the lack of affordable health insurance in the United States (US) is a known barrier to pre-emptive KT for low-income individuals with ESKD,${ }^{1}$ as Medicare benefits are reserved for older adults, the permanently disabled, and those who are dialysis-dependent. Several US states have expanded Medicaid under the Patient Protection and Affordable Care Act
\end{abstract}

Table 1 Characteristics of Medicaid-Covered Pre-emptive Transplant Recipients in Non-Expansion and Expansion States, Pre- and PostMedicaid Expansion

\begin{tabular}{|c|c|c|c|c|c|c|}
\hline & \multicolumn{2}{|l|}{ Pre-expansion } & \multirow{3}{*}{$p$ value $^{a}$} & \multicolumn{2}{|l|}{ Post-expansion } & \multirow{3}{*}{$p$ value $^{b}$} \\
\hline & Non-expansion state & Expansion state & & Non-expansion state & Expansion state & \\
\hline & $N=74$ & $N=235$ & & $N=103$ & $N=390$ & \\
\hline Age, median (IQR) & $46.0(35.0,57.0)$ & $47.0(33.0,55.0)$ & 0.40 & $47.0(36.0,56.0)$ & $46.0(34.0,55.0)$ & 0.34 \\
\hline Race & & & 0.71 & & & 0.05 \\
\hline White & $35(47.3 \%)$ & $113(48.1 \%)$ & & $54(52.4 \%)$ & $191(49.0 \%)$ & \\
\hline Black & $18(24.3 \%)$ & $50(21.3 \%)$ & & $25(24.3 \%)$ & $63(16.2 \%)$ & \\
\hline Hispanic & $18(24.3 \%)$ & $54(23.0 \%)$ & & $20(19.4 \%)$ & $95(24.4 \%)$ & \\
\hline Other & $3(4.1 \%)$ & $18(7.7 \%)$ & & $4(3.9 \%)$ & $41(10.5 \%)$ & \\
\hline Male sex & $34(45.9 \%)$ & $113(48.1 \%)$ & 0.75 & $52(50.5 \%)$ & $200(51.3 \%)$ & 0.89 \\
\hline BMI, median (IQR) & $28.2(23.0,31.5)$ & $27.2(23.3,31.2)$ & 0.69 & $29.2(25.5,33.0)$ & $28.3(24.0,32.7)$ & 0.38 \\
\hline Diabetes & $24(32.4 \%)$ & $72(30.6 \%)$ & 0.77 & $28(27.2 \%)$ & $112(28.7 \%)$ & 0.76 \\
\hline Educational attainment & & & 0.31 & & & 0.90 \\
\hline$<\mathrm{HS}$ & $6(8.1 \%)$ & $26(11.1 \%)$ & & $8(7.8 \%)$ & $28(7.2 \%)$ & \\
\hline HS graduate & $53(71.6 \%)$ & $175(74.5 \%)$ & & $75(72.8 \%)$ & $273(70.0 \%)$ & \\
\hline$\geq$ College graduate & $10(13.5 \%)$ & $16(6.8 \%)$ & & $17(16.5 \%)$ & $75(19.2 \%)$ & \\
\hline Missing/unknown & $5(6.8 \%)$ & $18(7.7 \%)$ & & $3(2.9 \%)$ & $14(3.6 \%)$ & \\
\hline Employment & & & 0.12 & & & 0.02 \\
\hline Not working & $59(79.7 \%)$ & $164(69.8 \%)$ & & $82(79.6 \%)$ & $257(65.9 \%)$ & \\
\hline Working & $8(10.8 \%)$ & $51(21.7 \%)$ & & $18(17.5 \%)$ & $105(26.9 \%)$ & \\
\hline Missing & $7(9.5 \%)$ & $20(8.5 \%)$ & & $3(2.9 \%)$ & $28(7.2 \%)$ & \\
\hline
\end{tabular}

Values presented as median (interquartile range) and $n(\%)$

$B M I$, body mass index; HS, high school; IQR, interquartile range

${ }^{a} p$ values comparing non-missing data from a chi-square test or a Wilcoxon Rank Sum test, as appropriate, among recipients in the pre-expansion period

${ }_{b}^{b}$ values comparing non-missing data from a chi-square test or a Wilcoxon Rank Sum test, as appropriate, among recipients in the post-expansion period

Published online August 19, 2019 
(ACA), extending Medicaid coverage to millions of previously uninsured low-income individuals ${ }^{2}$ including those with nondialysis-dependent kidney disease. ${ }^{3}$ The goal of this study was to determine whether Medicaid expansion was associated with changes in Medicaid coverage for pre-emptive living-donor KT (LDKT) and deceased-donor KT (DDKT) in the US.

\section{METHODS}

Using national data from the Organ Procurement and Transplantation Network, ${ }^{4}$ we performed a retrospective study of non-elderly US adults (age 21-64 years) who received preemptive KT between January 1, 2010, and December 31,

\section{a Living-donor preemptive kidney transplants}

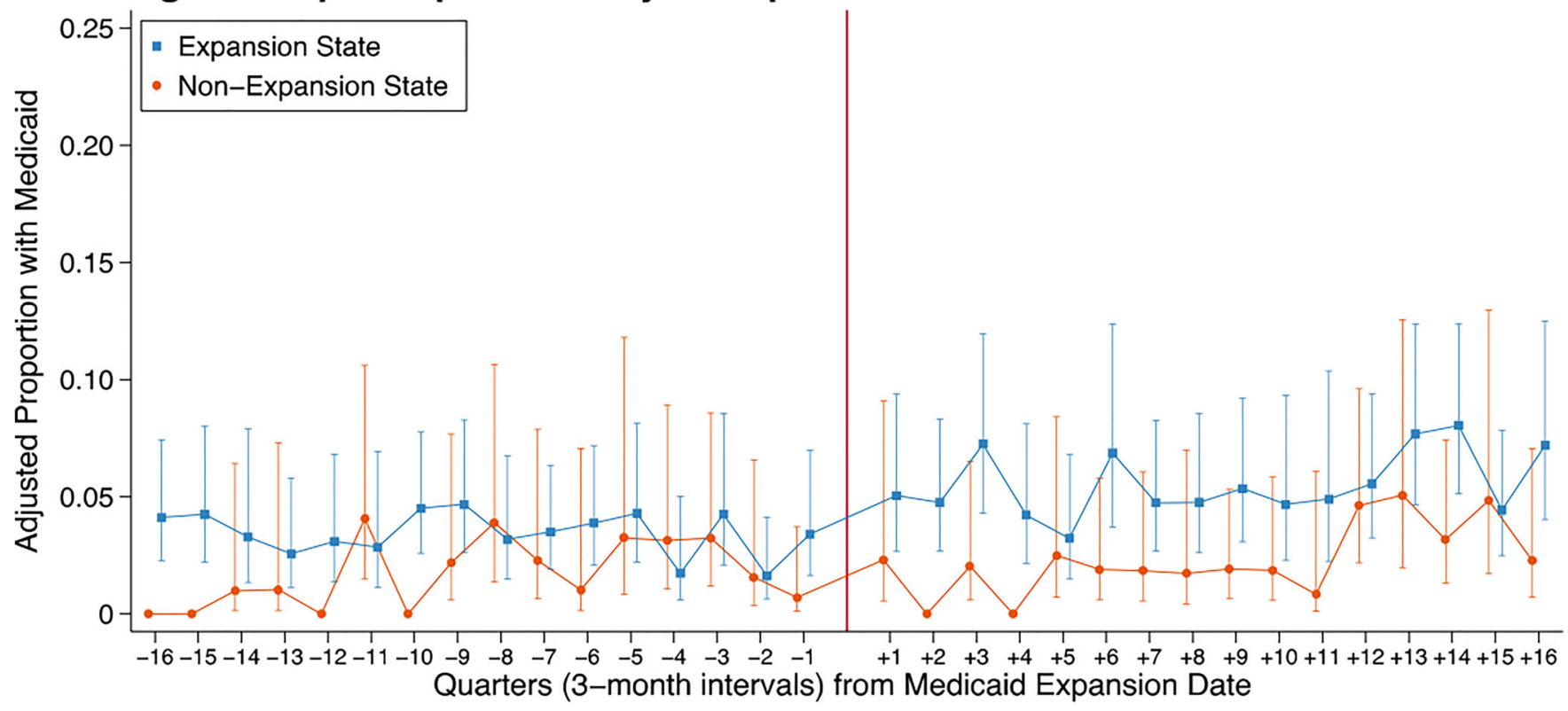

\section{b Deceased-donor pre-emptive kidney transplants}

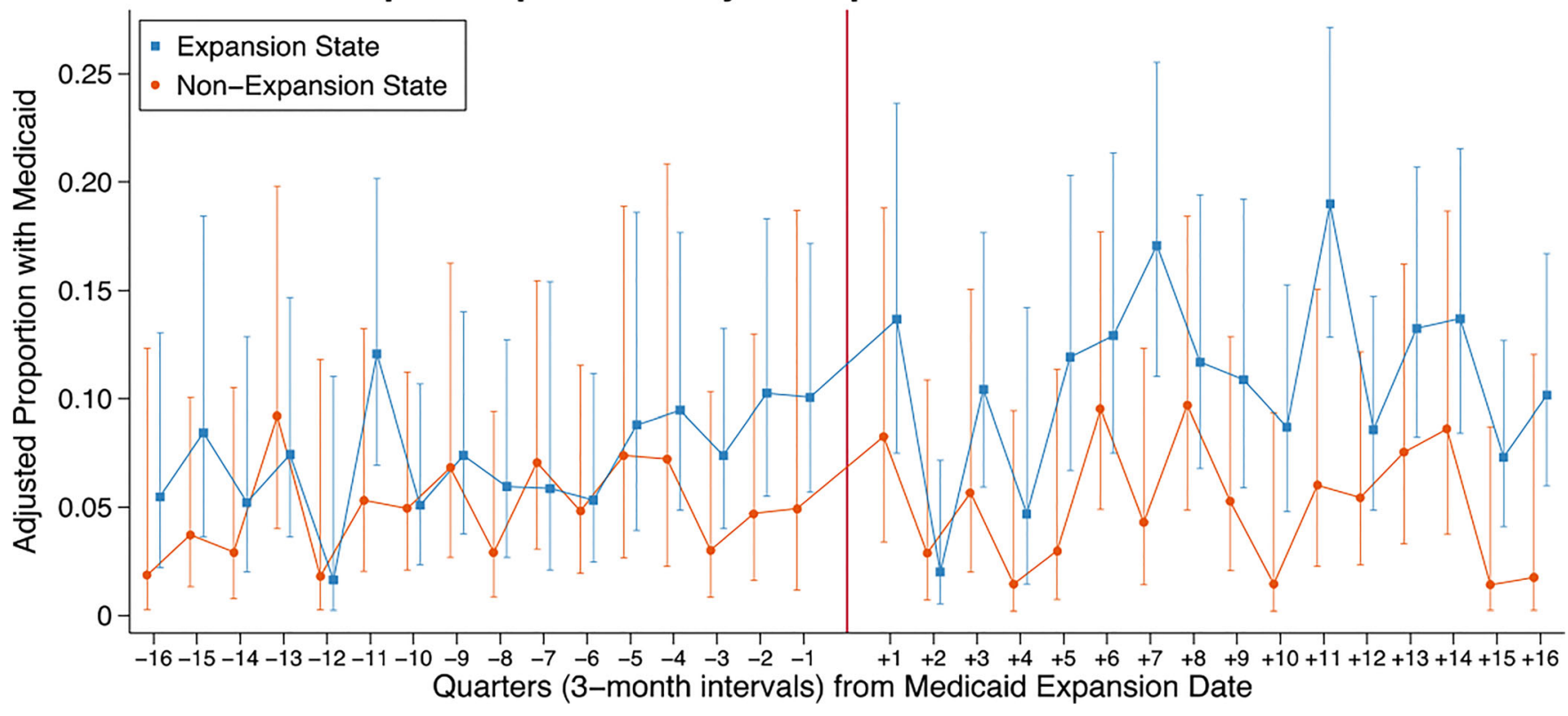

Figure 1 Adjusted proportion of non-elderly pre-emptive kidney transplants with Medicaid coverage, with 95\% confidence intervals. This figure displays results from an age, race, and sex-adjusted logistic regression model for pre-emptive kidney transplant recipient insurance type (Medicaid/other), comparing 19 non-expansion states to 31 expansion states (and the District of Columbia) for (panel a) living-donor preemptive kidney transplants and (panel b) deceased-donor pre-emptive kidney transplants. To account for different calendar dates of Medicaid expansion, results are presented as the number of quarters before and after a standardized Medicaid expansion date, where the date of Medicaid expansion is set to equal zero. The point estimate for each quarter indicates the adjusted proportion of all pre-emptive transplants in that quarter that was Medicaid-covered. The solid line indicates the calendar date of Medicaid expansion for expansion states, and January 1 , 2014 for non-expansion states. Blue squares represent proportions of Medicaid-covered pre-emptive transplants in expansion states, with $95 \%$ confidence intervals. Red circles represent proportions of Medicaid-covered pre-emptive transplants in non-expansion states, with $95 \%$ confidence intervals. 
2017. We excluded multi-organ recipients, those with noninsurance-based payment for KT $(n=31)$, residents of US territories, and those with missing data on state of residence. Our primary exposure was full implementation of Medicaid expansion under the ACA to include all non-elderly adults at or below $138 \%$ of the federal poverty level. Consistent with our prior approach, ${ }^{4}$ we standardized Medicaid expansion implementation dates for each state that expanded Medicaid during the study period $(n=31$ and the District of Columbia), ${ }^{2}$ and we included January 1, 2014, as the full implementation date for states that had earlier partial expansions of Medicaid. ${ }^{4}$ We compared the pre- and postimplementation periods in Medicaid expansion states to the periods before and after January 1, 2014, in nonexpansion states $(n=19)^{2}$ with respect to the following: (1) the proportion of DDKTs that were Medicaid-covered and (2) the proportion of LDKTs that were Medicaidcovered using chi-square tests.

We also compared national trends in Medicaid-covered preemptive DDKT and LDKT, respectively, between expansion and non-expansion states by estimating an age, race, and sexadjusted logistic regression model of pre-emptive KT insurance types (Medicaid/other) within each quarter (3-month period) of our study period. The Drexel University institutional review board approved the study. Analyses were performed using Stata14 (College Station, TX).

\section{RESULTS}

Among 15,775 non-elderly pre-emptive KT recipients, the median age was 51 years (interquartile range $42-58$ years), $56 \%$ were male, and $71 \%$ were white. After Medicaid expansion, Medicaid-covered pre-emptive KT recipients from expansion states were more likely to be minorities and to be employed than those from non-expansion states (Table 1). From the pre- to post-expansion periods, the total number of pre-emptive KTs with Medicaid coverage increased relatively by $37 \%$ in non-expansion states and by $66 \%$ in expansion states. The proportion of pre-emptive DDKTs with Medicaid coverage increased by 0.8 percentage points within non-expansion states (4.6 to $5.4 \%, p=$ 0.41 ) and by 3.8 percentage points in expansion states (7.3\% vs $11.1 \%, p<0.001)$. LDKT with Medicaid coverage increased by 0.7 percentage points in non-expansion states ( 1.7 to $2.4 \%, p=0.12$ ) and by 2.2 percentage points in expansion states $(3.4$ to $5.6 \%, p<0.001)$. In the adjusted quarterly trend analysis of insurance coverage for pre-emptive DDKT and LDKT, respectively (Fig. 1), increases in Medicaid-covered recipients were observable within three quarters of the expansion date in expansion states.

\section{DISCUSSION}

In this study, we found evidence that Medicaid expansion was associated with increases in the proportions of pre-emptive LDKTs and DDKTs, respectively, that were Medicaid-covered. These findings extend our prior work showing that Medicaid expansion was associated with a 59\% relative increase in Medicaid-covered pre-emptive KT wait-listings. ${ }^{4}$ Pre-emptive KT allows individuals with ESKD to avoid the morbidity and mortality associated with dialysis. However, KT is largely restricted to those with health insurance, a known contributor to socioeconomic disparities in rates of pre-emptive KT in the US. ${ }^{1,5}$ Given the ongoing coverage gap in states that did not expand Medicaid, the lack of affordable health insurance persists as a substantial barrier to pre-emptive KT for low-income individuals in the US with ESKD. ${ }^{4,}{ }^{6}$ An important limitation of our study is that the total population of low-income individuals in the US who may be eligible for pre-emptive KT is unknown. In summary, these results suggest that Medicaid expansion has enabled more low-income US individuals with chronic kidney disease to receive KT before requiring dialysis.

Corresponding Author: Meera N. Harhay, MD, MSCE; Department of Medicine, Division of Nephrology and Hypertension, Drexel University College of Medicine, 245 North 15th Street, Mailstop 437, Philadelphia, PA 19102, USA (e-mail: mnh52@drexel.edu).

Author Contributions $M N H, R M M$, and $M O H$ designed the study, analyzed the data, interpreted the data, and drafted and revised the manuscript; all authors approved the final version of the manuscript.

Funding Information MNH is supported by a grant (K23DK105207) from the National Institutes of Health (NIH)/National Institutes of Diabetes and Digestive and Kidney Diseases (NIDDK). MOH is supported by a grant (K99 HL141678) from the NIH/National Heart, Lung, and Blood Institute. This work was supported in part by Health Resources and Services Administration contract 234-2005-37011C.

\section{Compliance with Ethical Standards:}

The Drexel University institutional review board approved the study.

Conflict of Interest: The authors declare that they do not have a conflict of interest.

Disclaimer: The content is the responsibility of the authors alone and does not necessarily reflect the views or policies of the Department of Health and Human Services, nor does mention of trade names, commercial products, or organizations imply endorsement by the U.S. Government.

\section{REFERENCES}

1. Grams ME, Chen BP, Coresh J, Segev DL. Preemptive deceased donor kidney transplantation: considerations of equity and utility. Clin J Am Soc Nephrol. 2013;8(4):575-82.

2. Henry J. Kaiser Family Foundation 2017; https://www.kff.org/ health-reform/state-indicator/state-activity-around-expandingm e d i c a i d - und e r - the-a fford a b le - c a r e - a c t / ? 
currentTimeframe $=0 \&$ sortModel $=\% 7 \mathrm{~B} \% 22$ colId $\% 22: \% 22$ Location\%22,\%22sort\%22:\%22asc\%22\%7D Accessed on July 9, 2019.

3. Harhay MN, McKenna RM. The Affordable Care Act and Trends in Insurance Coverage and Disease Awareness Among Non-elderly Individuals with Kidney Disease. J Gen Intern Med. 2018.

4. Harhay MN, McKenna RM, Boyle SM, Ranganna K, Mizrahi LL, Guy S, et al. Association between Medicaid Expansion under the Affordable Care Act and Preemptive Listings for Kidney Transplantation. Clin J Am Soc Nephrol. 2018;13(7): 1069-78.

5. Purnell TS, Luo X, Cooper LA, Massie AB, Kucirka LM, Henderson ML, et al. Association of Race and Ethnicity With Live Donor Kidney
Transplantation in the United States From 1995 to 2014. JAMA. 2018;319(1):49-61.

6. Garfield R.; Damico A. 2017; . Henry J Kaiser Family Foundation at https://www.kff.org/uninsured/issue-brief/the-coverage-gap-uninsuredpoor-adults-in-states-that-do-not-expand-medicaid/ Accessed on July 9, 2019.

Publisher's Note Springer Nature remains neutral with regard to jurisdictional claims in published maps and institutional affiliations. 